\title{
Monitoring of a geothermal reservoir by hybrid gravimetry; feasibility study applied to the Soultz-sous-Forêts and Rittershoffen sites in the Rhine graben
}

\author{
Jacques Hinderer ${ }^{1 *}$, Marta Calvo ${ }^{1,2}$, Yassine Abdelfettah ${ }^{1,3}$, Basile Hector ${ }^{1}$, Umberto Riccardii ${ }^{4}$, Gilbert Ferhat ${ }^{1,5}$
} and Jean-Daniel Bernard ${ }^{\top}$

\author{
* Correspondence: \\ jacques.hinderer@unistra.fr \\ ${ }^{1}$ Institut de Physique du Globe de \\ Strasbourg UMR 7516 CNRS, \\ Université de Strasbourg, 5 rue \\ Descartes, Strasbourg 67084, France \\ Full list of author information is \\ available at the end of the article
}

\begin{abstract}
The study is devoted to the monitoring of a geothermal reservoir by hybrid gravimetry combining different types of instruments (permanent superconducting gravimeter, absolute ballistic gravimeter, and micro-gravimeters) and different techniques of measurements (both time-discrete and recording data collection). Using a micro-gravimetric repetition network around a reference station, which is regularly measured, leads to the knowledge of the time and space changes in surface gravity. Such changes can be linked to the natural or anthropic activities of the reservoir. A feasibility study using this methodology is applied to two geothermal sites in the Alsace region (France) of the Rhine graben. We show the results in terms of gravity double differences from weekly repetitions of a network of 11 stations around the geothermal reservoir of Soultz-sous-Forêts, separated into 5 loops during July-August 2013 and 2014 as well as preliminary results from 2 stations near Rittershoffen (ECOGI). We point out the importance of a precise leveling of the gravity points for the control of the vertical deformation. A first modeling of surface gravity changes induced by realistic geothermal density perturbations (Newtonian attraction) is computed in the frame of the existing geological model and leads to gravity changes below the $\mu \mathrm{Gal}$ level being hence undetectable. However, and for the same case, borehole gravity modeling showed a significant anomaly with depth that can be used as a complementary monitoring method. We show that in the limit of our uncertainties (SD $~ 5 \mu \mathrm{Gal}$ ), we do not detect any significant gravity change on the geothermal site of Soultz in agreement with the fact that there was indeed no geothermal activity during our analysis period. On the contrary, the measurements near Rittershoffen show a signal above the noise level which correlates in time with a production test but cannot be explained in terms of Newtonian attraction effects according to our basic numerical simulation.
\end{abstract}

\section{Background}

Gravimetry is generally used as a prospecting method for underground structures at various scales (volcanoes, geothermal, gas and oil reservoirs, mineral resources, stratigraphy) and contributes to the static imagery in addition to other methods like magneto-tellurics (e.g., Volpi et al. 2003, Newman et al. 2008; Geiermann and Schill 2010) or seismics (Concha et al. 2010; Sanjuan et al. 2010). Time-lapse gravimetry can

\section{Springer}

(c) 2015 Hinderer et al. Open Access This article is distributed under the terms of the Creative Commons Attribution 4.0 International License (http://creativecommons.org/licenses/by/4.0/), which permits unrestricted use, distribution, and reproduction in any medium, provided you give appropriate credit to the original author(s) and the source, provide a link to the Creative Commons license, and indicate if changes were made. 
also be a monitoring tool of any underground or surface mass redistribution and has many applications in volcanology (magmatic chamber evolution), hydrology (water storage changes in the critical zone), and geothermics.

Gravity has the potential to obtain valuable information on water storage changes and water flows using non-destructive observations of a geothermal reservoir with spatial resolution ranging from meter to kilometer.

Moreover, new instruments are available, like the portable superconducting gravimeter iGrav (Warburton et al. 2010) or will be available soon, like the cold atom absolute gravimeter (Bidel et al. 2013; Wu et al. 2014; Merlet et al. 2010) that will even improve in the near future this potentiality.

Several studies have introduced the concept of hybrid (resp. super-hybrid) gravimetry (Okubo et al. 2002; Sugihara and Ishido 2008; Hector et al. 2015) that is the optimal combination of two (resp. three) types of gravimeters (see Fig. 1 and Table 1):

- a permanent gravimeter which allows a precise continuous monitoring of the time-varying gravity at a reference station located on the investigated site; in order to be able to retrieve the long-term behavior, one uses generally a superconducting gravimeter (SG) rather than a spring meter because of its very small instrumental drift (a few $\mu \mathrm{Gal} /$ year) and better precision (0.1-0.01 $\mu \mathrm{Gal}$ ) (Hinderer et al. 2007);

- a ballistic absolute gravimeter (AG) that allows to control the long-term gravity changes by repeated parallel recording over short periods of time with the SG (Sugihara and Ishido 2008; Jacob et al. 2008), as well as to check the calibration stability of the SG;

- a spring relative gravimeter (RG) to repeat observations on a micro-gravimetric network around the reference station by successive loops in order to gain more insight into the space-time changes in the investigated region (Naujoks et al. 2008; Gehman et al. 2009; Jacob et al. 2010; Hare et al. 2008; Davis et al. 2008).

In this feasibility study, we do not have any SG measuring continuously on site but rather use a link to a SG in operation in the Strasbourg Gravimetric Observatory $40 \mathrm{~km}$ away. This impacts clearly the absolute accuracy of our local network even if we performed two AG measurements on our reference station GPK1 showing no gravity

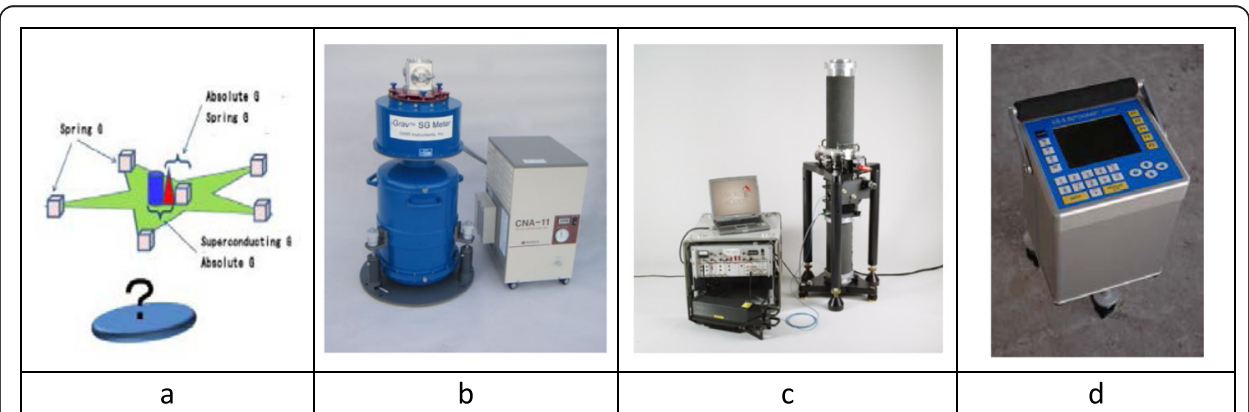

Fig. 1 The concept of hybrid gravimetry to investigate an underground reservoir (a) with the combination of superconducting gravimeter (SG) (b), absolute gravimeter AG (c), and relative spring meter RG (d) (adapted from Sugihara et al. 2013) 
Table 1 Characteristics of the different gravimeters involved in hybrid gravimetry

\begin{tabular}{|c|c|c|c|}
\hline Gravimeter & Precision & Stability & Use \\
\hline Superconducting (SG) & $<0.1-0.01 \mu \mathrm{Gal}$ & Small drift (1-2 $\mu \mathrm{Gal} /$ year) & High-precision continuous monitoring \\
\hline Absolute (AG) & $1-2 \mu \mathrm{Gal}$ & No drift & Absolute reference + long-term evolution \\
\hline Relative spring (RG) & $5 \mu \mathrm{Gal}$ & $\begin{array}{l}\text { Large drift (tens or hundreds } \\
\text { of } \mu \text { Gal/day) }\end{array}$ & Prospection + repetition network \\
\hline
\end{tabular}

variation over a period of about 6 months (see "Absolute gravity measurements at the reference site GPK1" section).

Hybrid gravimetry is often coupled to other types of measurements like precise positioning, hydrometeorology (rain), or hydrology (piezometry, soil moisture) and brings new insights in several research topics. Progress has been made in hydrogravimetry in the study of water storage changes using mainly SG and RG measurements (Longuevergne et al. 2009; Creutzfeldt et al. 2010; Naujoks et al. 2010; Pfeffer et al. 2011; Hinderer et al. 2012; Hector et al. 2015). Similarly, new results were obtained from hybrid gravimetry in volcanology using mostly AG and RG measurements (Greco et al. 2012; Hautmann et al. 2010; Bataglia et al. 2008) that allow to determine also absolute changes in the local network which were unknown in previous studies based only on RG observations (e.g., Jousset et al. 2000). Finally, many studies in geothermics are now available using the concept of hybrid or super-hybrid gravimetry (Nishijima et al. 2000; Oka et al. 2010; Sofyan et al. 2010; Sugihara and Ishido 2008; Takemura et al. 2000).

There are several causes leading to density changes of geothermal origin like pore space opening/closing in hydrofracturing or hydroshearing, fluid infiltration, heating/ cooling, as well as mineralization (De Vivo et al. 1989; Schultz et al. 2012) but the main causes for gravity changes are due to fluid injection and/or withdrawal (Allis et al. 2001; Hunt and Bowyer 2007; Hunt and Graham 2009).

Hence, it is expected that surface gravity observations can be sensitive to these changes provided that the data are corrected for body and ocean tides, air pressure effect and hydrogravimetric effects due to aquifers, and water content in the vadose zone (cf. Fig. 2).

In Fig. 2, the conical shape of influence (footprint) is due to the fact that the lateral extension of a layer has to increase with depth to produce the same surface gravity effect (Hector et al. 2014).

The density (and mass) changes of geothermal origin will then alter surface gravity by direct Newtonian attraction but also possibly indirectly via the vertical surface displacement generated by poro-elasticity. It is therefore of primary importance to always combining gravity observations with precise geodetic measurements (leveling, GPS, and SAR); in principle, the best option is to co-locate both gravity and leveling stations, simultaneously measured for the control of the vertical deformation and the study of the time variable vertical gravity gradient which is highly sensitive to the sub-surface mass redistribution (Hunt et al. 2002).

Time-lapse gravimetry helps to monitor the behavior of a geothermal reservoir, in its natural state with no anthropic perturbation but mostly when transient effects due to stimulation by injection/withdrawal occur. One key point is the long-term evolution of the reservoir (Sofyan et al. 2011). 


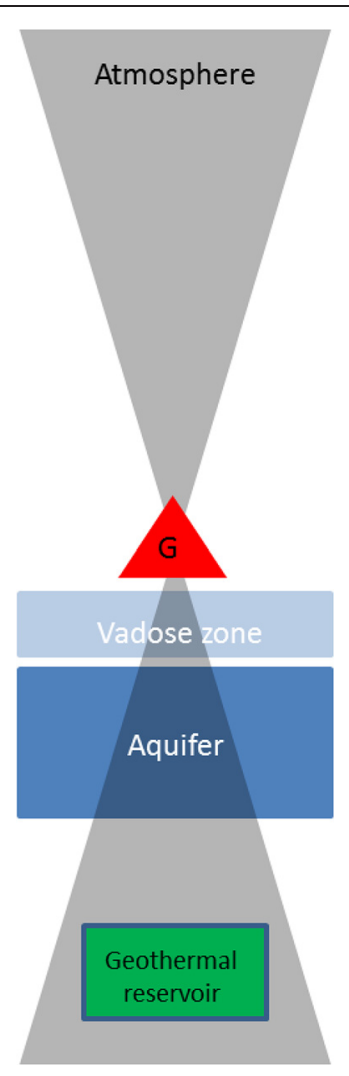

Fig. 2 Schematics of surface gravity changes of geothermal origin. A gravimeter located at the Earth's surface will be sensitive to effects coming from the above atmosphere and from different underground contributors (vadose zone, aquifer, geothermal reservoir)

In this paper, we present the first monitoring results obtained for the Soultz and Rittershoffen (NE Alsace, France) geothermal sites. The methodology, the data processing, and forward modeling as well as the results obtained between July 2013 and August 2014 are mainly presented and discussed. The PyGrav code we developed to optimize the data processing and to reduce the data uncertainties is also presented.

\section{Methods}

In this section, we first introduce the micro-gravimetric network that was set up on the Soultz and Rittershoffen geothermal sites as well as the measurement protocol. We present then the absolute gravity observations, which were done with FG5\#206 AG at the reference site of the network, as well as the continuous series at the same site obtained from a Scintrex CG5 gravimeter during a 34-day time span. We introduce also the precise geodetic positioning we use to control the vertical deformation. We finally discuss the approach we follow to model the gravity effects of any geothermal reservoir.

\section{Micro-gravimetric network}

The location of the stations used in our gravimetric hybrid approach is schematically shown on Fig. 3. STJ9 is the site of the Strasbourg Gravimetric Observatory, north of Strasbourg city, where a superconducting gravimeter (SG GWR C026) belonging to the 


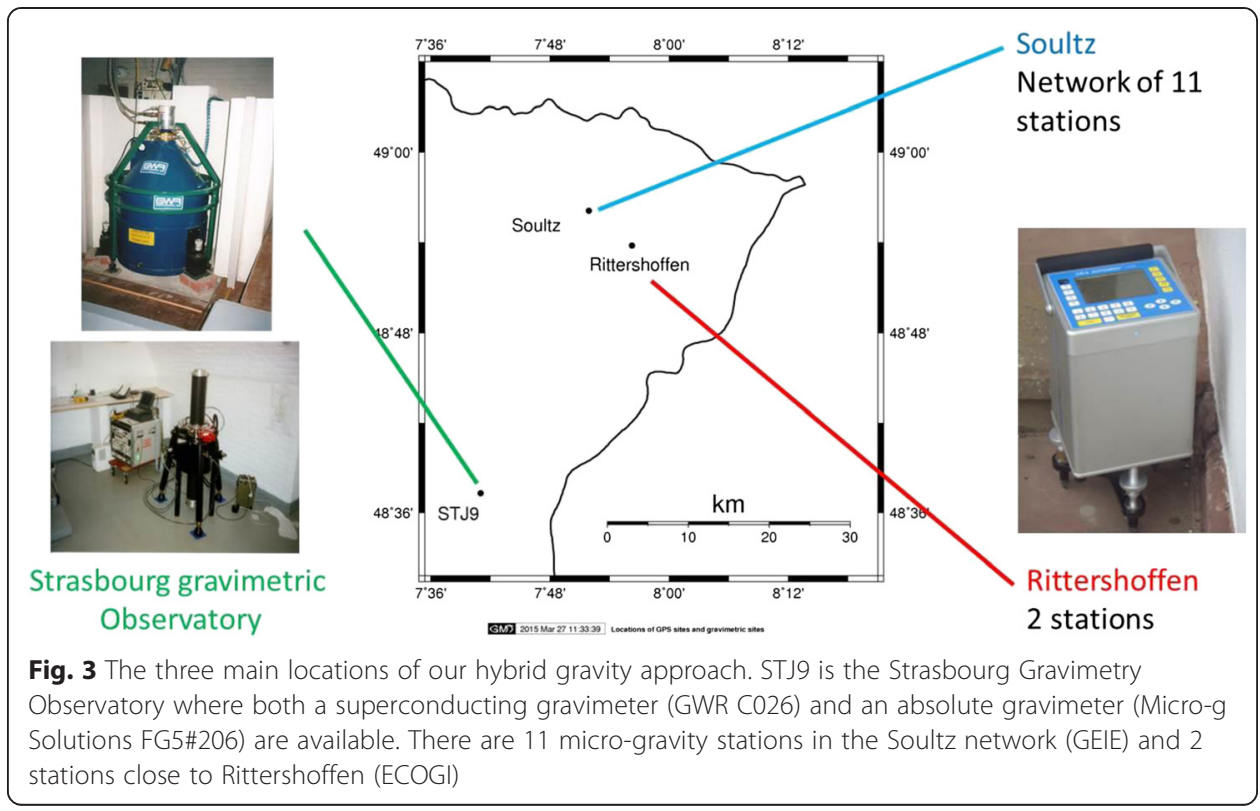

GGP (Global Geodynamics Project) is continuously recording since 1996; in this station, there are also regular absolute gravity observations done in parallel with an absolute gravimeter (AG) FG5\#206. In the lack of a SG being present on site, we will use this station to tie our network.

The Soultz geothermal site is the first EGS (Enhanced Geothermal System) demonstration site producing electricity in France. Several wells from 2200- to 5000-m depth have been drilled, stimulated, and circulated within deep naturally fractured granite (Genter et al. 2010). The injection well (GPK1) was drilled to a depth of $3600 \mathrm{~m}$ and production well (GPK2) even deeper $(5000 \mathrm{~m})$ allowing initially two-well hydraulic circulation. Later on, other injection wells were added to form a multi-well system to monitor, measure, and manage the geothermal system during exploitation (Genter et al. 2013).

The network around the Soultz-sous-Forêts geothermal site is composed of 11 stations where the reference station is GPK1 (close to the injection borehole of the same name) (see Fig. 4).

The 11 stations were selected around the geothermal site to surround the injection and extraction boreholes (GPK1 and GPK2) within 4-5 km range; only stable locations like forecourts of churches or concrete paving stones are kept. These 11 stations are measured with a Scintrex CG5 gravimeter in 5 different loops starting and ending at the reference station GPK1 and having 4 or 5 stations each one with the constraint of 1 or 2 stations common to two loops (cf. Table 2). In this way, only 3 stations (excluding the base station) are repeated in different loops which give only $30 \%$ of redundancy of the (Soultz) network. It would be better to repeat more stations but this would be more time-consuming since the present protocol already requires 2 and half days of measurements per weekly survey.

At each measurement point, the CG5 is first leveled and the operator waits $15 \mathrm{~min}$ to allow the instrument to become quiet after transportation. If needed, it is again precisely leveled before a sequence is launched of 5-10 consecutive cycles of 90-s duration each depending on the convergence of the results of each cycle (mean gravity after $90 \mathrm{~s}$ ). 


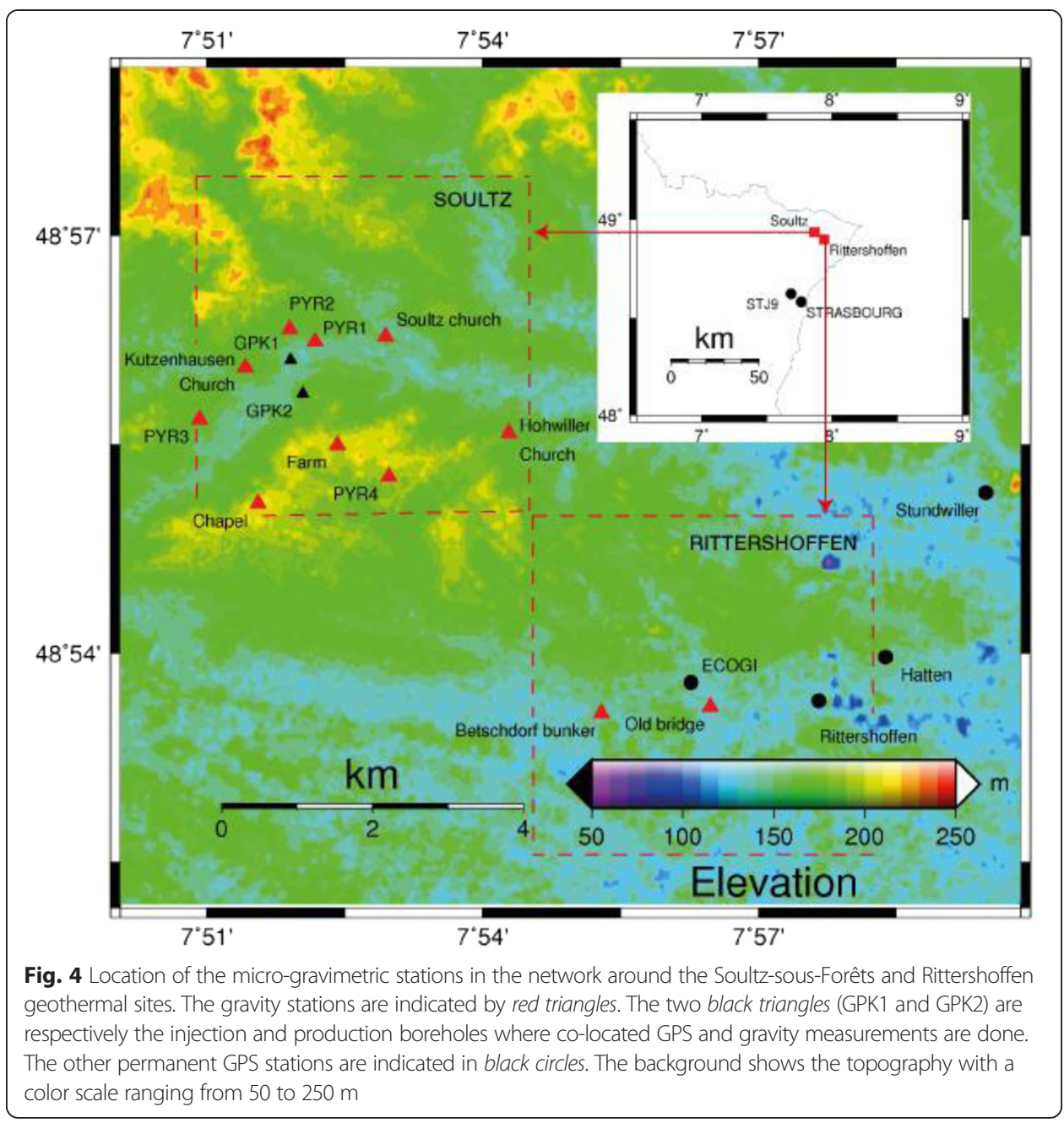

Prior to the measurements, the long-term drift is removed with a linear fitting, and the residual drift is checked to be less than $4 \mu \mathrm{Gal} / \mathrm{h}$. Thus, if 3 consecutive measurements are within a 1-3 $\mu \mathrm{Gal}$ range and no residual drift is observed, the measurements are stopped.

An example of a station (Pyr 3) of this network is given in Fig. 5 where the tripod uses a concrete floor built around a pyramidal protection of a borehole. The location

Table 2 Description of the loops of the Soultz gravity network

Loop 1

GPK1 - Pyr1 - Pyr2 - Kutzenhausen church - GPK1

Loop 2

GPK1 - Kutzenhausen church - Pyr3 -Soultz church - GPK1

Loop 3

GPK1 - Soultz church - Pyr4 - farm - GPK1

Loop 4

GPK1 - chapel - farm - GPK2 - GPK1

Loop 5

GPK1 - Soultz church - Hohwiller church - GPK1 


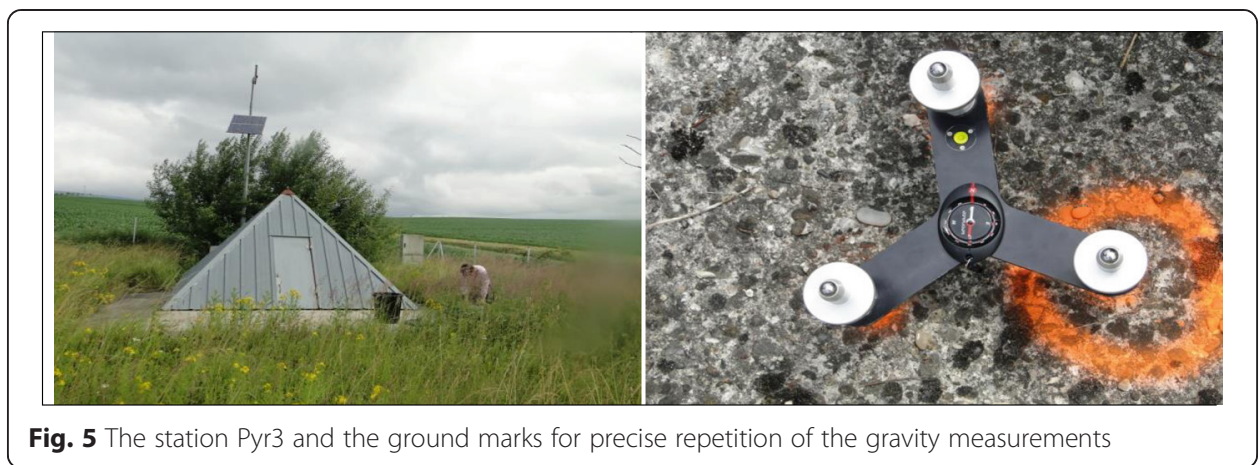

for the gravimeter tripod is indicated by marks on this concrete to ensure a precise repetition of the gravity measurements.

In 2014, being informed that a production test would occur in August 2014, we have added 2 more stations around the Rittershoffen geothermal site where the ECOGI experiment takes place. With a geological context similar to the Soultz-sous-Forêts project, this geothermal project is dedicated to an industrial use for heat application (24 MWth at $160{ }^{\circ} \mathrm{C}$ ). The first well was drilled in 2012 and a second one in spring 2014, both to a depth close to $2500 \mathrm{~m}$.

One station is very close to the site (old bridge) and the second one in the nearby village (Betschdorf). A denser network like the Soultz one with 10-15 stations will be established in the future (still this year) for a better monitoring of the ECOGI site.

Each survey starts and ends from Strasbourg Gravimetric Observatory enabling us to connect the local network of Soultz and Rittershoffen to a known reference which is monitored by both continuous (SG) and absolute (AG) instruments. There is hence one tie per survey (i.e., per week) between Strasbourg and Soultz. There is a weekly repetition of this survey during the summer months (July and August) in 2013 and 2014 leading to 14 surveys over a period of 4 months. The variability of the 2014 weekly amplitude of the 59-GPK1 ties using CG5 RG is found to be of the order of 5-7 $\mu \mathrm{Gal}$; this value has to be compared to the difference in the absolute values at GPK1 using FG5 AG between April and October 2013 which is $0.3 \pm 3.4 \mu \mathrm{Gal}$ (see "Absolute gravity measurements at the reference site GPK1" section). In fact, since we have continuous SG measurements at our reference station J9, we also computed the difference between the April and October 2013 J9-GPK1 ties using both SG and AG measurements which leads to a value of $3.7 \pm 3.4 \mu \mathrm{Gal}$ since there is a $4.0-\mu \mathrm{Gal}$ gravity increase at $\mathrm{J} 9$ station from the SG data corrected for the same effects (tides, air pressure, polar motion) as the FG5.

\section{Absolute gravity measurements at the reference site GPK1}

The first determination of the absolute gravity at the reference site GPK1 of the Soultz network was done in April 2013 and repeated in October 2013. An example of the scatter of the drop values (every $10 \mathrm{~s}$ ) and of the set values (mean values of 100 successive drops every hour) is shown on Fig. 6. The results of the two measurement campaigns are given in Table 3. 


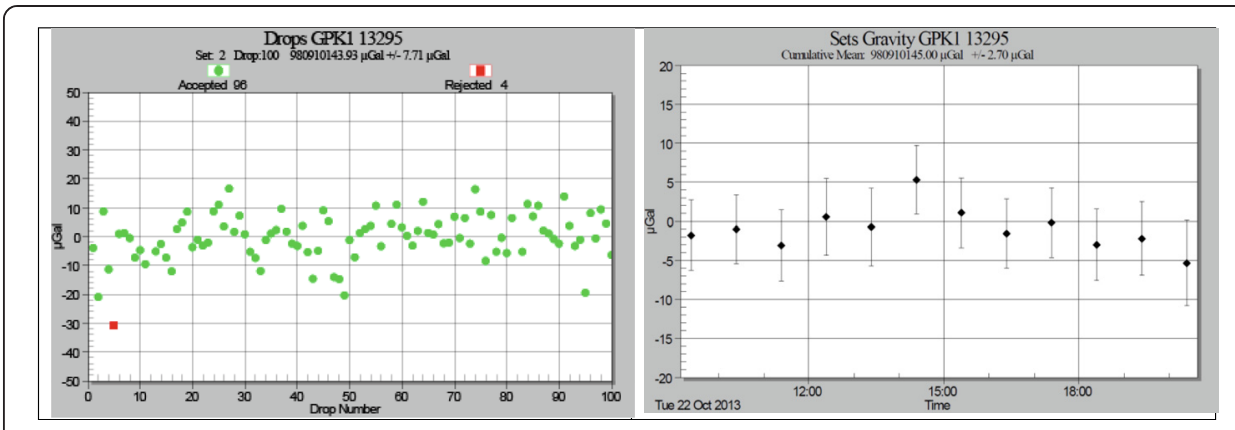

Fig. 6 Drop and set scatter of the absolute gravity observations at GPK1 in October 2013

It turns out that our reference site GPK1 seems to be very stable with no significant change in gravity in the 6-month interval (within the uncertainty of $3.4 \mu \mathrm{Gal}$ inferred from our two AG observations). This stability has to be checked again in the future.

The measurement of the absolute gravity at Soultz and Strasbourg Observatory led also to establish a quick calibration line between these two points which helps to control the calibration factor of the Scintrex gravimeter over time. The amplitude of this calibration line is however modest $(26.746 \mathrm{mGal})$ and smaller than the line of 323.170-mGal amplitude between Chelmos (1740-m altitude) and Temeni (sea level) in the Gulf of Corinth (Greece) which was measured in December 2013 by our FG5 AG. The CG5 gravimeter which was available for our 2013 study was calibrated using this line to a precision slightly better than $10^{-4}$. The CG5 used in 2014 is a new instrument acquired a few months before the summer surveys and calibrated by the manufacturer.

It is also important to point out here that the repetition of a micro-gravimetric network has to be done with a calibrated instrument (if possible always the same). Calibration accuracy can be better than $10^{-4}$ when a large amplitude absolute baseline is used (Debeglia and Dupont 2002) and this is in general enough for micro-gravimetric surveys; in our network, the largest gravity difference between two stations is about $16 \mathrm{mGal}$ and the calibration error leads then to $1.6-\mu \mathrm{Gal}$ gravity change which is smaller than the mean network loop uncertainty of $5 \mu \mathrm{Gal}$ discussed in "Data processing" section. However, calibration changes with time and can reach $10^{-3}$ over a 2-year period (Jacob et al. 2010) emphasizing the fact that a regular check of the stability of the calibration factor is needed.

\section{Continuous relative measurements at GPK1}

In order to obtain local tidal parameters for solid Earth and ocean loading tides, a continuous record at GPK1 was collected GPK1 with a Scintrex CG5 gravimeter. The time span covers the period from 16 April 2013 to 21 May 2013 (Fig. 7).

The analysis of the data set using ETERNA 3.4 (Wenzel 1996) shows that the determination of large tides in the semi-diurnal and diurnal bands is satisfactory with

Table 3 Absolute gravity determinations at the reference site GPK1

\begin{tabular}{llll}
\hline Date & Duration (hours) & Gravity $(\mu \mathrm{Gal})$ & Uncertainty $(\mu \mathrm{Gal})$ \\
\hline $22 / 10 / 2013$ & 11 & 980910145.0 & 2.7 \\
$16 / 04 / 2013$ & 5 & 980910145.3 & 2.1 \\
\hline
\end{tabular}



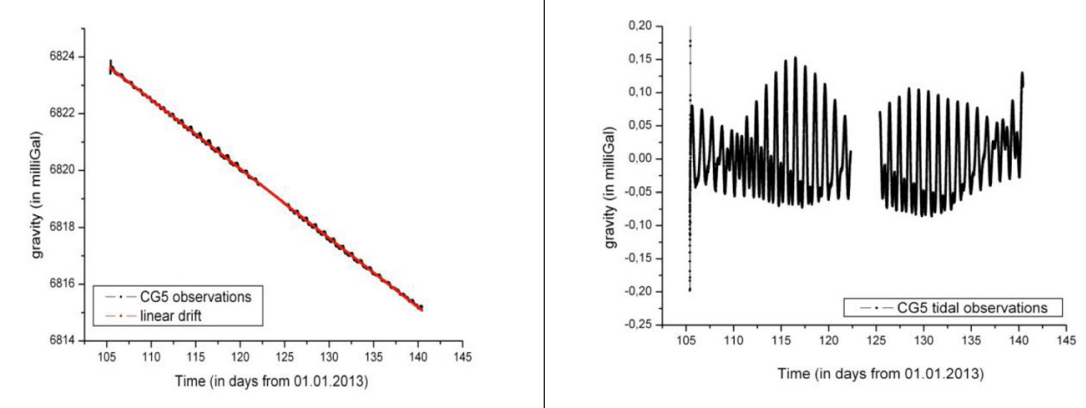

Fig. 7 Time-varying gravity recorded with a Scintrex CG5 at the base station (GPK1) of the Soultz network. Long-term drift and linear approximation (left); tidal fluctuations after drift removal (right)

results in close agreement with those obtained from the superconducting gravimeter C026 in Strasbourg (cf. Fig. 8). However, the determination of smaller amplitude tides shows more discrepancies. Notice also the strong differences in the tidal uncertainties with respect to the SG observations for the same time period. We also found a factor close to 35 in the standard deviation (SD) of the Scintrex CG5 and the GWR C026 gravity residuals. A tidal prediction shows that the gravity difference between Strasbourg and Soultz (40-km distance) leads to a very small residual tidal signal with a standard deviation of $0.45 \mu \mathrm{Gal}$. We decided to use in our corrections tidal parameters for the solid Earth and ocean loading tides that originate from the analysis of long record of the Strasbourg SG (see e.g. Calvo et al. 2014).

\section{Precise geodetic positioning}

Gravity changes $\delta_{g}$ due to underground mass redistribution must be corrected for any vertical height change $h$ since we have the following relationship:

$$
\delta_{g}=-\frac{2 g_{0}}{a} h+2 \pi G \rho h
$$

where $g_{0}$ is the mean surface gravity, $a$ the mean Earth's radius, $\rho$ the mean density of the crust, and $G$ the gravitational constant.

The first term in right hand side of Eq. 1 is usually called the free air correction and amounts to about $-0.31 \mu \mathrm{Gal} / \mathrm{mm}$; the second term is the effect of an infinite Bouguer
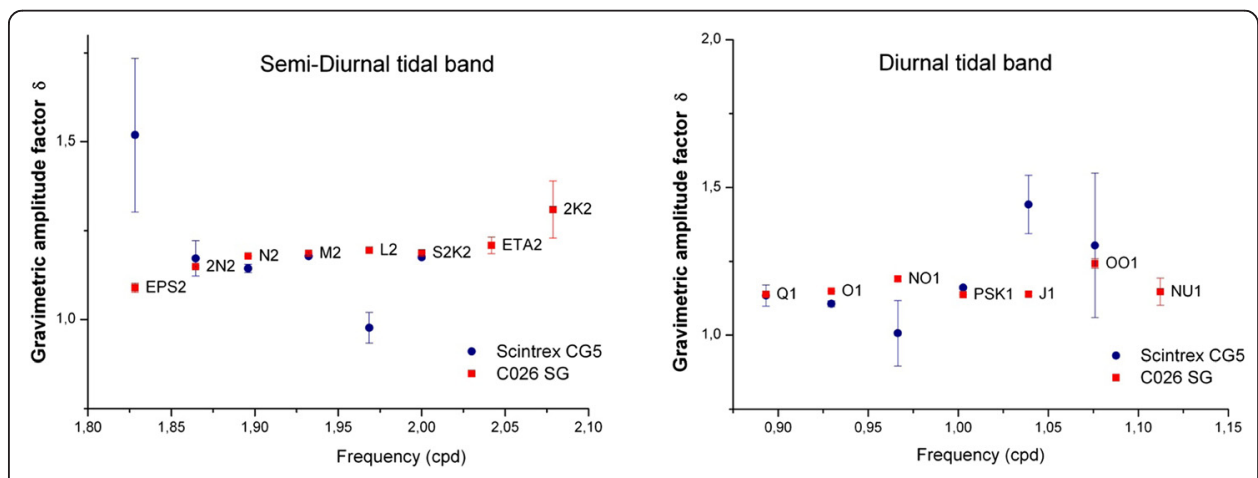

Fig. 8 Gravimetric amplitude factors in the semi-diurnal and diurnal frequency bands 
slab of density $\rho$. The sum of the two effects is $-0.2 \mu \mathrm{Gal} / \mathrm{mm}$ assuming a mean crustal density of $2670 \mathrm{~kg} \mathrm{~m}^{-3}$.

This is why a precise control of the station elevations is required. This is achieved in our project by high-precision geodetic leveling which should lead to a few millimeter precision on all the points of the network.

To perform a rigorous vertical control, all gravimetric sites are equipped with a leveling benchmark. During May 2014, a large leveling network ( $40 \mathrm{~km}$ long) connecting the 13 gravimetric sites was observed in 4 main loops and a small loop around ECOGI site (Ferhat et al. 2014). The closure loops show an equivalent precision of $1.5 \mathrm{~mm} / \mathrm{km}$ for the main loops and $0.5 \mathrm{~mm} / \mathrm{km}$ for the small loops (Ferhat et al. 2014). This accuracy is large enough to guarantee a vertical precision better than a few millimeter required for gravimetric variation interpretation. From a preliminary investigation based on a repetition of the leveling network 3 times in 2014 on the small loop around ECOGI, it turns out that most of the height changes are less than 1 or $2 \mathrm{~mm}$. Moreover, 2 continuous GPS (cGPS) stations have been installed within the leveling network and 4 cGPS stations around ECOGI site (cf. Fig. 4) to insure long-term stability analysis. Again, the analysis of the vertical component does not show any significant motion exceeding 1 or $2 \mathrm{~mm}$ (Heimlich et al. 2013).

\section{Gravity modeling of geothermal effects}

Besides our observational approach, we also wanted to estimate the surface gravity changes that might be expected from any deep geothermal activity. If the density changes linked to such an activity are spatially known, one is then able to predict if the surface gravity effects are detectable and even to set up the optimal station positioning. Unfortunately, we do not have here this knowledge and must rely on very simple (simplistic) approximations to compute the order of magnitude of the gravity effects.

Classically, two main formulas are used to compute the surface gravity change as a function of the mass change:

$$
\Delta g \approx G \Delta M / d^{2}
$$

assuming that all the mass anomaly $\Delta M$ is concentrated at a point with depth $d$ (Mogi approach), or:

$$
\Delta g=B \Delta M / A,
$$

Assuming now that the mass anomaly is spread over a surface $A$ (Bouguer slab approach); $B$ is equal to $42 \mu \mathrm{Gal} \mathrm{m}{ }^{2} \mathrm{~T}^{-1}$. The gravity change is expressed in $\mu \mathrm{Gal}(B=42)$ if the mass is expressed in tons $(\mathrm{T})$ and the surface in square meters $\left(\mathrm{m}^{2}\right)$ (Allis and Hunt 1986). In this latter case, as can be proven most simply with Gauss's law for gravity (La Fehr 1965), the gravity change is independent on the depth but this is only valid if the lateral extension is much larger than the depth.

As these two approaches are oversimplified, we choose to use more realistic approach. The purpose is to use the 3D geological model for the investigated zone, which is meshed with finite element method (tetrahedrons) and then compute the gravity effect at the surface resulting from this discrete model (Fig. 9). This reference model is then perturbed by locating specific density changes in depth according to realistic stimulations of the geothermal reservoir (flow rate, total period of injection, depth of 


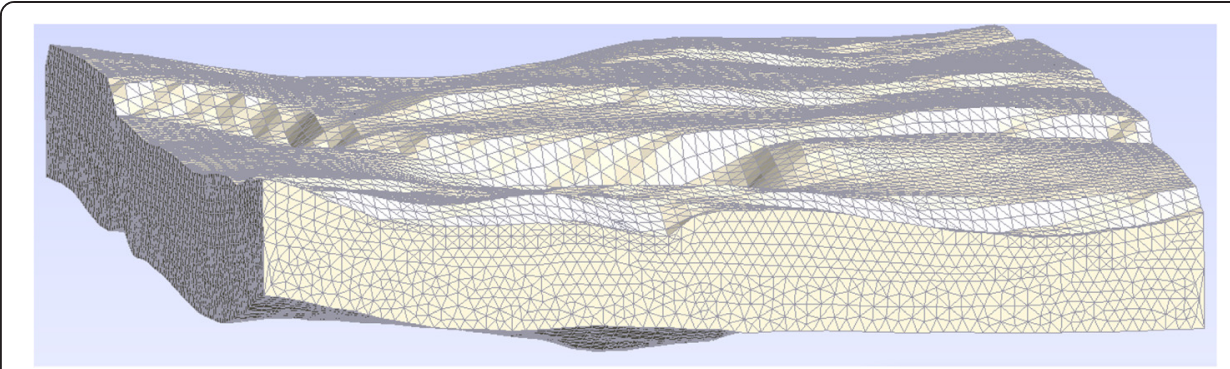

Fig. 9 Geological model for Soultz-sous-Forêts from (Baillieux 2012) showed without tertiary layer and without bedrock. The tetrahedron meshing is achieved using GMSH tool of Geuzaine and Remacle (2009)

injection, etc.). Then, the misfit between the new resulting gravity and the reference one is computed, leading to the gravity change of geothermal origin.

The 3D forward modeling for tetrahedron geometry is achieved using following formulae (e.g., Pohanka 1988):

$$
g(r, \varepsilon)=-G \rho \sum_{k=1}^{K} n_{k} \sum_{l=1}^{L(k)} \Phi_{k, ~}
$$

with

$$
\Phi_{k, l}=\phi\left(U_{k, l}(r), V_{k, l}(r), W_{k, l}(r), z_{k}(r), \varepsilon\right)
$$

where $r$ is the distance between the gravity station and the element unit, $\rho$ is the density value of the element, $n_{k}$ is the normal vector to the surface $k$ formed by $l$ edges. $U$, $V$, and $W$ are the geometrical function in the $x, y$, and $z$ directions. The value $\varepsilon$ is an infinitesimal number $\left(\varepsilon \leq 10^{-6}\right)$ to avoid some singularities; it represents at the maximum only $1 \mu \mathrm{Gal}$ in the total gravity values. Additional information on the forward modeling and sensitivity analysis as well as the computed data uncertainty can be found in Abdelfettah et al. (2014).

The possible gravity effect caused by geothermal utilization is assessed using 3D forward modeling and then the misfit is computed between before and after geothermal events (e.g., hydraulic stimulation, production, water injection, etc.). In our approach and in order to simulate the real conditions, the measurement stations are located on the real topography and the reference model is of any $3 \mathrm{D}$ complexity. More important, our formalism can be applied to any geothermal context.

As an example, we located at a depth of $2 \mathrm{~km}$ a mass excess of 0.173 megatons (MT) which would result from a continuous water injection at a rate of $20 \mathrm{l} / \mathrm{s}$ during 100 days. This injection rate is comparable to what was indeed used in hydraulic tests done in 2010 and 2011 in Soultz during periods of several months (Genter et al. 2013) but, in standard operation, the circulation of Soultz HDR reservoir is balanced between injection and production (Baumgärtner et al. 1998). Note that this mass change is much smaller than the 1200 MT value quoted in Allis et al. (2001) for the Geysers geothermal reservoir in several years leading to several hundreds of $\mu \mathrm{Gal}$ gravity changes. The mass excess was distributed inside a prism of dimension $100 \times 100 \times 100 \mathrm{~m}$ located and centered at a depth of $2 \mathrm{~km}$. This leads to a density increase of $173 \mathrm{~kg} \mathrm{~m}^{-3}$ (6.65\% in proportion) generating a surface gravity variation of $0.6 \mu \mathrm{Gal}$ which is maximal at the 
center above the mass anomaly (Fig. 10). The black square represents the projection at the surface of the perturbed deep volume, and the points are the stations where the gravity change has been computed.

The geological model (Fig. 9) for our study zone extracted from Baillieux (2012) is derived from seismic and borehole data and consists in a 6 layer model with dimension $\sim 30 \times 20 \times 5 \mathrm{~km}$. The geological stratigraphy is simplified to model only the Tertiary, Jurassic, Keuper, Muschelkalk, Buntsandstein, and the Basement horizons. These horizons showed vertical variations up to $500 \mathrm{~m}$ when crossing the faults (Baillieux 2012). The sedimentary layers show east dip as well as the top of the basement. The thicker geological unit is mainly the Tertiary which can reach $750 \mathrm{~m}( \pm 320 \mathrm{~m})$, whereas the other sedimentary units do not exceed $373 \mathrm{~m}$, the thickness of the Buntsandstein for example (Baillieux 2012 and references in there). The geothermal reservoir in the simulated water injection area is located in the granitic basement unit below 1500-m depth.

It is obvious from Fig. 10 that the predicted gravity change at the surface is very small, below the $\mu \mathrm{Gal}$ level, and hence undetectable in micro-gravimetry. We would like to test our modeling with observations; since there is presently no geothermal activity in Soultz, our experiment is merely a "null test" where we check that no gravity change occurs. This leads to a " $\mathrm{T}_{\mathrm{o}}$ " state acting as a reference for the future monitoring during production.

The predicted changes are very small because of the large distance from the surface to the source anomaly located at a depth of $2000 \mathrm{~m}$. Therefore, it is worth to see what signal would be observed when measuring with a borehole gravimeter closer to the source anomaly. Figure 11 shows the borehole gravity prediction as a function of depth for the same source anomaly (mass perturbation of $0.173 \mathrm{MT}$ at 2-km depth) as the one used in Fig. 10. It is obvious that the gravity changes become large when one measures close to the anomaly; it is for instance reaching $250 \mu \mathrm{Gal}$ at a distance of $100 \mathrm{~m}$. Changes of a few tens or hundreds of $\mu \mathrm{Gal}$ are easily measurable today with borehole

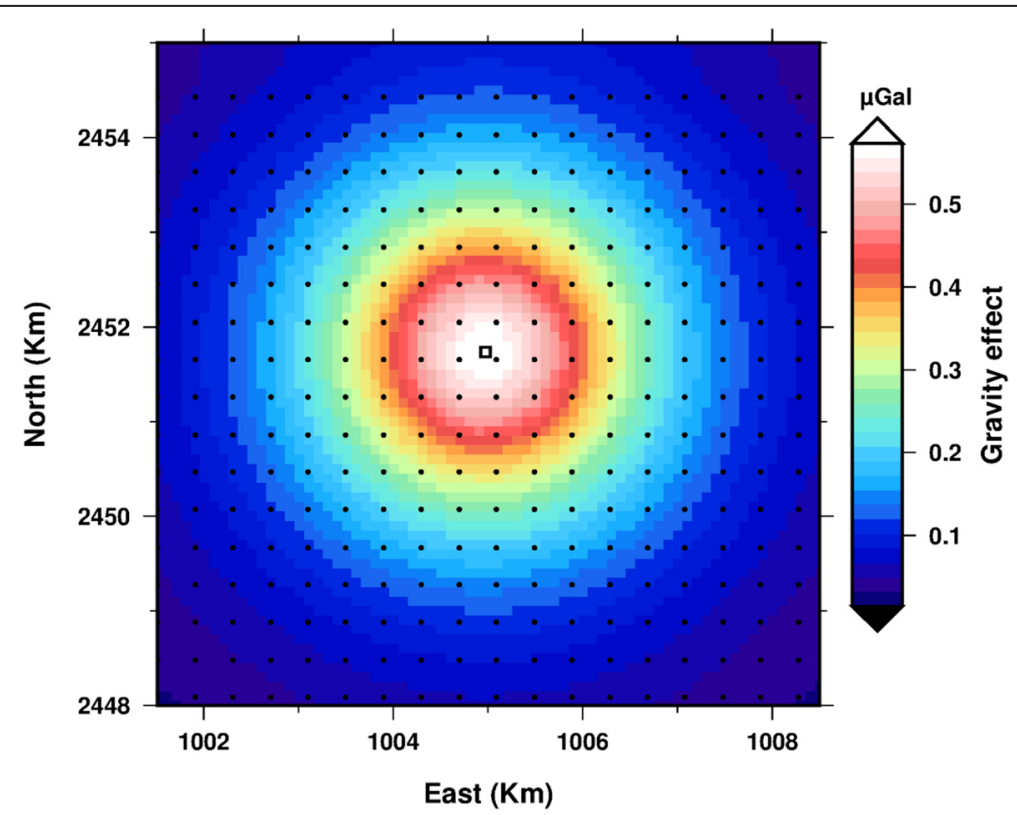

Fig. 10 Surface gravity effect (in $\mu \mathrm{Gal}$ ) due to a mass perturbation of 0.173 MT located at 2-km depth within a prism of dimension $100 \times 100 \times 100 \mathrm{~m}$ 


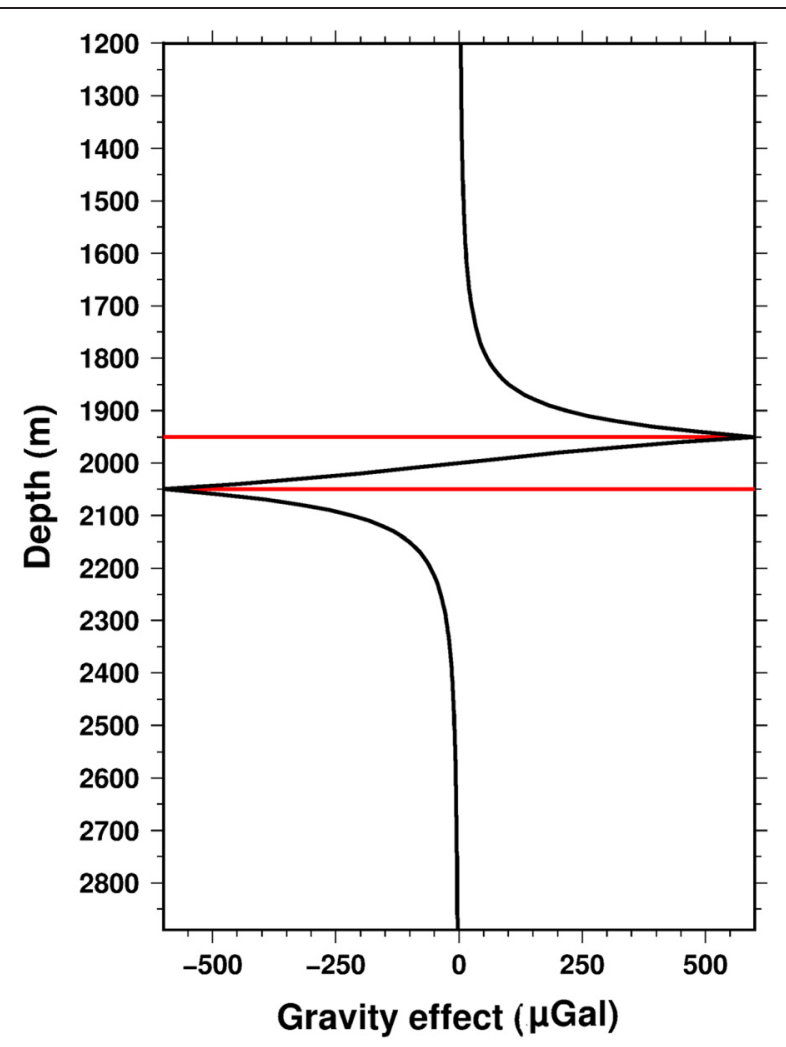

Fig. 11 Borehole gravity effect as a function of the depth due to a mass perturbation of 0.173 MT located at 2-km depth. The two horizontal red lines show the top and bottom of the layer (100 $\mathrm{m}$ thick) where the source anomaly occurs

gravimeters which are sensors able to measure gravity as deep as several thousand meters with a few $\mu$ Gal precision (Nind et al. 2007; Seigel et al. 2009).

\section{Data processing}

The repetition of a micro-gravimetric network, where $x_{0}$ and $t_{0}$ are the reference point and time, leads to the following formula for the gravity double differences at point $x$ and time $t$ :

$$
D g_{x-x_{0}}^{t-t_{0}}=\left(g_{x}-g_{x_{0}}\right)_{t}-\left(g_{x}-g_{x_{0}}\right)_{t_{0}}
$$

To process the data, we developed a software written using a Python language called PyGrav in order to homogenize and concatenate current processing codes like Matlab scripts, MCGravi (Beilin 2006), CGxTool (Gabalda et al. 2003), or ETERNA (Wenzel 1996). This code is very appropriate for all kinds of gravity surveys (static, time-lapse) and allows in particular an easy reprocessing of repeated micro-gravity networks. It has a user-friendly interface for handy and fast treatment of the raw gravity data at every station of the network (see Fig. 12).

Fully manual or automatic selection is possible according to specific thresholds in tilt, standard deviation, or duration of the gravity observations. Each selected measurement is then corrected for tides and air pressure and the software allows to remove the instrumental drift on all the chosen loops of the network. This is done using the least-square inversion scheme described in Hwang et al. (2002). This first step leads to the gravity simple 


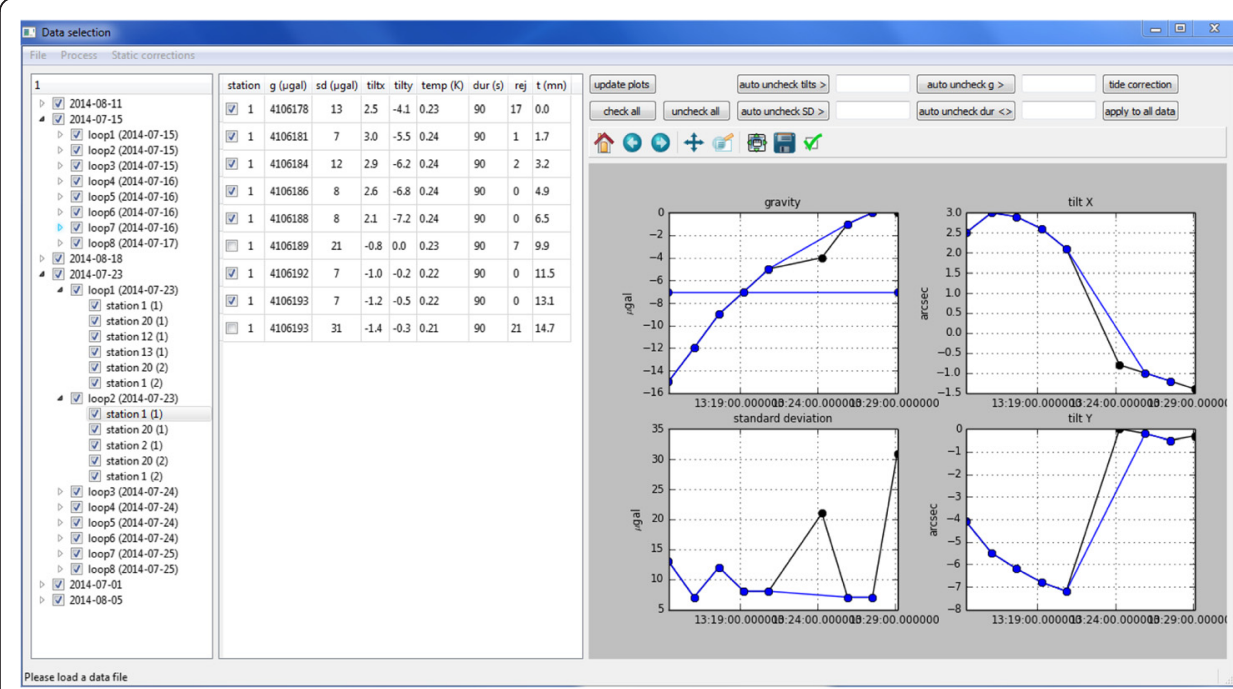

Fig. 12 An example of a graphical window of PyGrav software

differences between the reference point and any point of the network; the standard deviation is computed following Hwang et al. (2002) as the square root of the posteriori variance resulting from the inversion scheme. When different repetitions of the network are done, gravity double differences are computed according to Eq. 5; the standard error (uncertainty) on a gravity change between two surveys and for a specific station is the square root of the quadratic sum of respective station standard errors for each survey.

\section{Results and discussion}

The processing of the 8 surveys in 2013 and 6 surveys in 2014 leads first to the simple differences (Fig. 13). This plot shows the gravity differences in mGal as a function of the station number where the base station GPK1 (code 1) is set to 0 . The variation range below $17 \mathrm{mGal}$ is mainly a consequence of the height differences among the stations and the regional density structure and any smaller variation (typically < tens of $\mu \mathrm{Gal}$ for the 2014 surveys as shown below) in time due to hydrology or geothermics is of course undetectable on this plot. The stations from 1 to 11 correspond to the Soultz network. Stations 12 and 13 around Rittershoffen are only available in 2014.

The computation of the double differences leads to a tremendous decrease in the amplitude of the gravity variations between 2013 and 2014 with values of several hundreds of $\mu \mathrm{Gal}$ in 2013 and in the range of a few $\mu \mathrm{Gal}$ to less than $30 \mu \mathrm{Gal}$ in 2014 . Similarly, there is roughly one order of magnitude reduction in the uncertainties (standard deviation) in 2014 with respect to 2013 as shown by Table 4; the 2014 uncertainties are small ranging from 2.6 to $6.6 \mu \mathrm{Gal}$ for the 6 available surveys.

Since the measurement protocol (number of stations per loop, number of loops, duration of each measurement, environmental conditions) is identical in 2013 and 2014, we attribute this decrease to the use of a different instrument. Both instruments are Scintrex CG5 models but the older instrument used in 2013 was known to be unstable after transportation. In 2014, we acquired a new CG5 and the older one was sent back to the manufacturer for test and it turned out that this instrument was defective and needed to be fixed. We believe that our poor results in 2013 are mostly due to the poor 


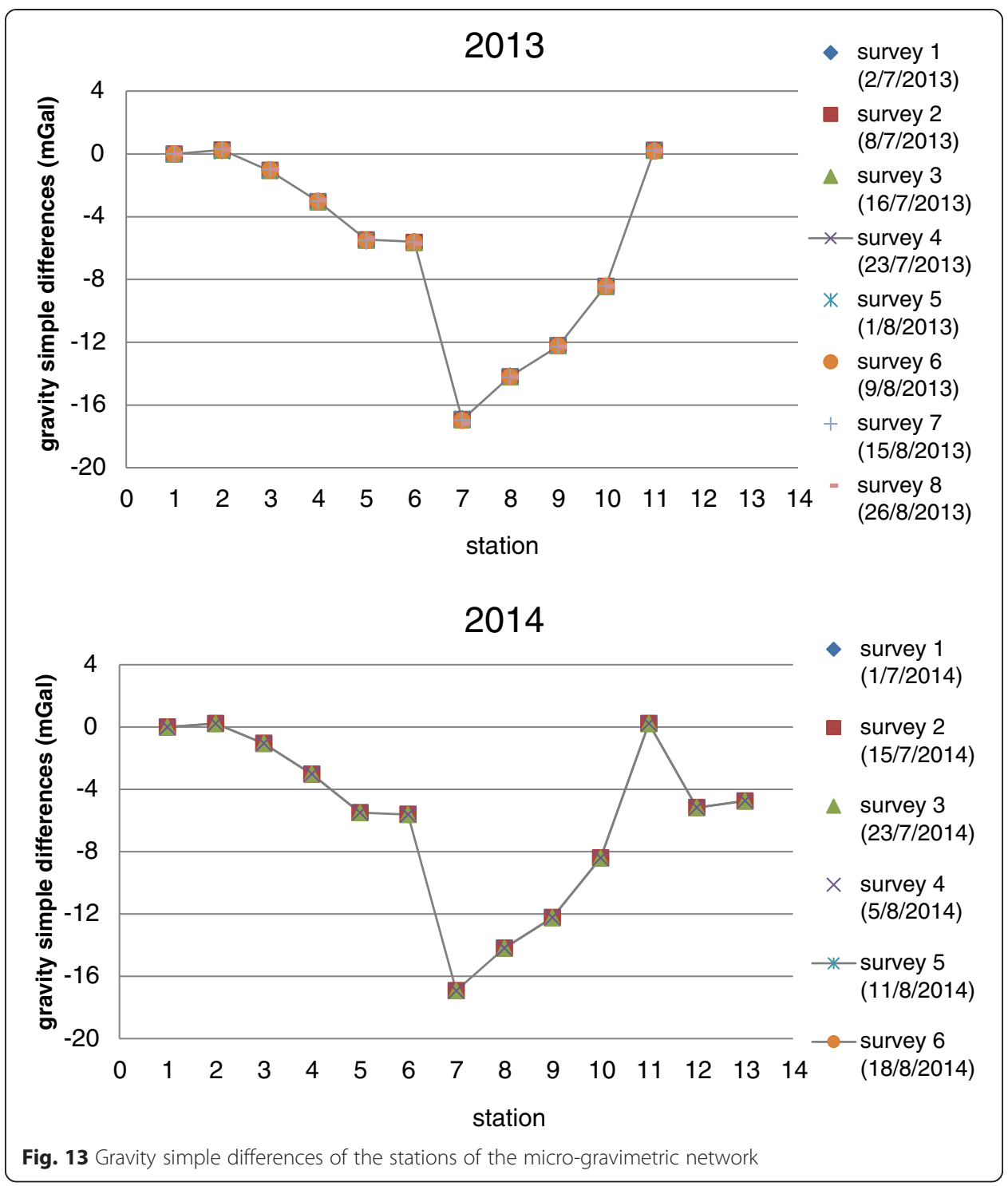

performances of the instrument. Since the 2013 campaign is useless, we focus now on the 2014 results in Fig. 14.

The variations in time are now much smaller with amplitude in the range of a few $\mu$ Gals almost never exceeding $10 \mu \mathrm{Gal}$. These changes are linked to several processes including vertical deformation, underground water redistribution (soil water content + water table), and possibly deeper geothermal contributions.

Almost all observed changes in the Soultz network (stations 1-11) are within the rectangular uncertainty zone and are hence not significant. In other terms, we do not observe any gravity change that exceeds our measurement precision.

The lack of detectable gravity changes indicated by our results for 2014 is in agreement with the fact that during this period, the geothermal activity was completely stopped in Soultz. When this activity will restart as expected in 2016 after major improvements in the central geothermal system, the induced gravity changes should still be small according to our (very) simple modeling and hardly observable by our network 
Table 4 Average standard deviation (SD) for each survey in 2013 and 2014

\begin{tabular}{lllllllll}
\hline Survey 2013 & July & \multicolumn{7}{c}{ August } \\
Day & 2 & 8 & 16 & 23 & 1 & 9 & 15 & 26 \\
SD $(\mu$ Gal) & 64.9 & 51.8 & 47.1 & 49.7 & 52.6 & 50.1 & 53.6 & 56.1 \\
Survey 2014 & July & & & August & & & \\
Day & 1 & 15 & 23 & 5 & 11 & 18 & \\
SD $(\mu$ Gal) & 2.6 & 3.2 & 5.8 & 6.6 & 5.8 & 5.6 & \\
\hline
\end{tabular}

and related uncertainty. A more precise computation will be done according to known input parameters like production/injection flow rate and stimulation duration.

Stations 12 and 13 around the Rittershoffen geothermal site show larger changes (reaching $25 \mu \mathrm{Gal}$ ) that are largely above our precision level and coincide with the start of well production tests at ECOGI beginning in August 2014. However, we need to have additional measurements to confirm the correlation between gravity and geothermal activity, especially having in mind that the Rittershoffen gravity loop is longer than the other loops near Soultz, which may deteriorate the drift correction of the micro-gravimeter. Moreover, our simple modeling has shown that gravity changes due to reasonable amount of injected mass are below $1 \mu \mathrm{Gal}$; we must be cautious on the origin of the changes which may be due to more superficial hydrological effects. However, notice that an increase of $10 \mu \mathrm{Gal}$ would require a water table increase of $25 \mathrm{~cm}$ (or $25 \mathrm{~cm} / \varphi$ where $\varphi$ is the porosity). We plan to acquire in the future piezometric data close to our investigated site to estimate this contribution.

\section{Conclusions}

Since the successive surveys in 2013 of the Soultz network can be dismissed because of an instrument defect, we basically only rely on the 6 surveys performed in summer 2014 using a new instrument. The time changes of the weekly repetitions of the stations are clearly small and mostly within the uncertainty level of the order of $5 \mu \mathrm{Gal}$. We have to repeat again these measurements in summer 2015 to check that the changes from 1 year to the next are also small, especially in the lack of geothermal

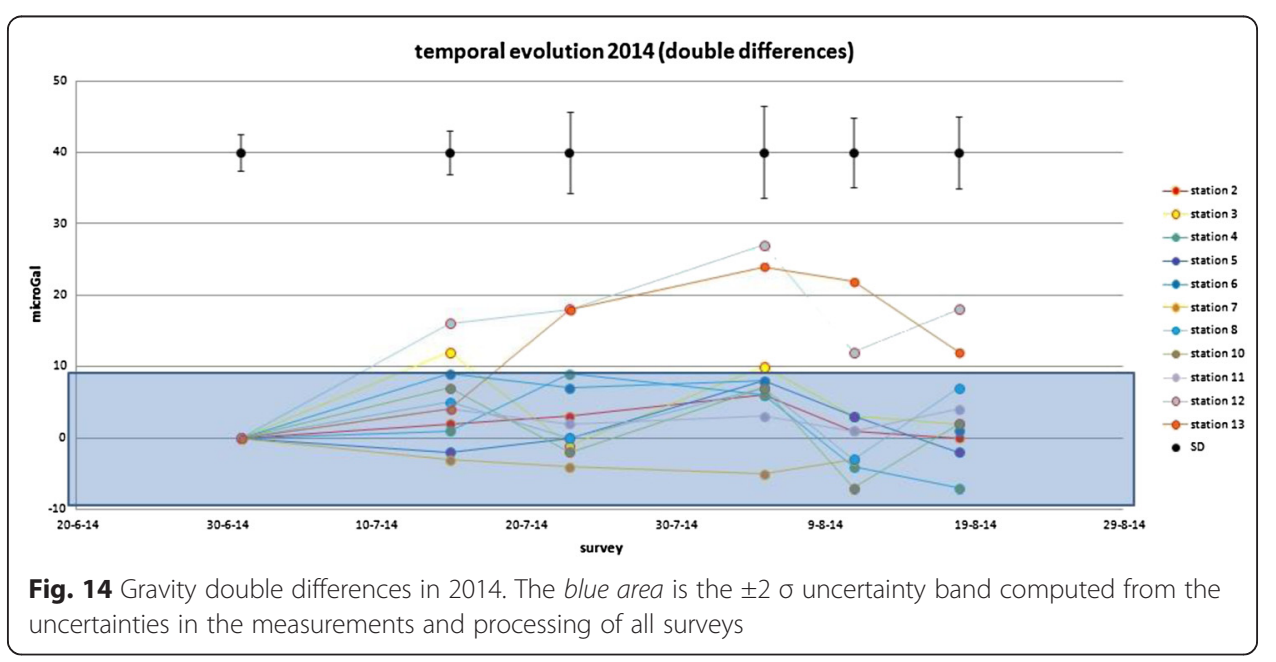


activity. If this is true, we will then have a well-defined reference network to detect the possible gravity changes that might occur when the geothermal plant will be restarted in 2016. The comparison of the uncertainties in the ties between the local reference station (GPK1) and the external reference station (J9 Observatory) shows that the use of absolute measurements at GPK1 combined with continuous SG observations at J9 leads to better results than CG5 RG ties alone. It is also obvious that the ideal case would be to install at GPK1 a permanent SG regularly checked with FG5 measurements as suggested in a true hybrid gravimetric approach.

The only observed significant changes in 2014 close to the ECOGI site in Rittershoffen that are possibly related to the injection tests at the same period rely only on two stations. We plan to densify in the future the network around ECOGI with additional stations to check the stability of the Rittershoffen network in the lack of activity in summer 2015. We also intend to detect the gravity signature of the future tests planned end of 2015 and to monitor the gravity change during the 2016 production period.

The rather large distance of the mass sources in deep geothermal reservoirs $(2.5 \mathrm{~km}$ for Rittershoffen and $5 \mathrm{~km}$ for Soultz) leads to very small surface signals, at least from the purely Newtonian point of view. However, borehole gravimetric modeling showed that a significant signal arises from water injection according to depth, when the source-sensor distance decreases.

\section{Competing interests}

The authors declare that they have no competing interests.

\section{Authors' contributions}

$\mathrm{JH}$ was the coordinator of the research project on the gravity monitoring of a geothermal field and wrote the paper. UR, MC and JDB were involved in the micro-gravity measurements and data processing. GF provided the height control by leveling measurements. YA performed the modeling of the surface and borehole gravity effects caused by geothermal activity. $\mathrm{BH}$ wrote the Pygrav code used to treat the gravity data. All authors read and approved the final manuscript.

\section{Acknowledgements}

This study was supported by Labex G-EAU-THERMIE project (Investissements d'Avenir), France and by the Institute for Nuclear Waste Disposal (INE)- Karlsruhe Institute for Technology (KIT), Germany.

\section{Author details}

${ }^{1}$ Institut de Physique du Globe de Strasbourg UMR 7516 CNRS, Université de Strasbourg, 5 rue Descartes, Strasbourg 67084, France. ${ }^{2}$ Observatorio Geofísico Central, IGN, Madrid, Spain. ${ }^{3}$ Institut für Nukleare Entsorgung INE, Karlsruher Institut für Technologie (KIT), Karlsruhe, Germany. ${ }^{4}$ Dipartimento di Scienze della Terra, dell'Ambiente e delle Risorse (DiSTAR), Università "Federico II" di Napoli, Naples, Italy. ${ }^{5}$ INSA Strasbourg, 24 boulevard de la Victoire, Strasbourg 67084, France.

Received: 31 March 2015 Accepted: 4 August 2015

Published online: 07 September 2015

\section{References}

Abdelfettah Y, Schill E, Kuhn P (2014) Characterization of geothermally relevant structures at the top of crystalline basement in Switzerland by filters and gravity forward modelling. Geophys J Int 199(1):226-241. doi:10.1093/gji/ ggu255

Allis RG, Hunt TM (1986) Analysis of exploitation-induced gravity changes at Wairakei geothermal field. Geophysics 51:1647-1660

Allis R, Gettings P, Isherwood WF, Chapman DS (2001) Precision gravity changes at the Geysers geothermal reservoir, 1975 -2000. Proceedings Twenty-Sixth Workshop on Geothermal Reservoir Engineering Stanford University, Stanford, California

Bailleux P (2012) Multidisciplinary approach to understand the localization of geothermal anomalies in the upper Rhine graben from regional to local scale, PhD Thesis, University of Neuchâtel, Switzerland, 131 pp.

Battaglia M, Gottsmann J, Carbone D, Fernandez J (2008) 4D volcano gravimetry. Geophysics 73:WA3-WA18. doi:10.1190/1.2977792

Baumgärtner J, Gérard A, Baria R, Jung R, Tran-Viet T, Gandy T, Aquilina L, Garnish J (1998) Circulating the HDR reservoir at Soultz: maintaining production and injection flow in complete balance. Proceedings, 23rd Workshop on Geothermal Reservoir Engineering, Stanford University, Stanford, CA 
Beilin J (2006) Apport de la gravimétrie absolue à la réalisation de la composante gravimétrique du Réseau Géodésique Français, Master Thesis. Inst. Géogr. Natl, Paris

Bidel Y, Carraz O, Charriere R, Cadoret M, Zahzam N, Bresson A (2013) Compact cold atom gravimeter for field applications. Appl Phys Lett 102 (14): doi:10.1063/1.4801756

Calvo M, Hinderer J, Rosat S, Legros H, Boy JP, Ducarme B, W Zürn (2014) Time stability of spring and superconducting gravimeters through the analysis of very long gravity records, J. of Geodyn 80:20-33. doi:10.1016/j.jog.2014.04.009

Concha D, Fehler M, Zhang H, Wang P (2010) Imaging of the Soultz enhanced geothermal reservoir using microseismic data. Proceedings Thirty-Fifth Workshop on Geothermal Reservoir Engineering Stanford University, Stanford, California

Creutzfeldt B, Güntner A, Thoss H, Merz B, Wziontek H (2010) Measuring the effect of local water storage changes on in situ gravity observations: case study of the Geodetic Observatory Wettzell. Germany Water Resour Res 46, W08531. doi:10.1029/2009WR008359

Davis K, Li Y, and Batzle M, (2008) Time-lapse gravity monitoring: a systematic 4D approach with application to aquifer storage and recovery. Geophysics 73, doi: 10.1190/1.2987376.

Debeglia N, Dupont F (2002) Some critical factors for engineering and environmental microgravity investigations, J. Applied Geophysics, 50(4):435-454.

De Vivo B, Belkin HE, Barbieri M, Chelini W, Lattanzi P, Lima A, Tolomeo L (1989) The Campi Flegrei (Italy) geothermal system: a fluid inclusion study of Mofete and S. Vito fields. J Volcanol Geotherm Res 36:303-326

Ferhat G, Patoine V, Clédat E (2014) Leveling network for surface deformation monitoring along Soultz-sous-Forêts and Rittershoffen geothermal sites, France. European Geothermal Workshop, Karlsruhe, Germany

Gabalda G, Bonvalot S, Hipkin R (2003) Interactive computer program to process Scintrex CG-3/3M gravity data for high resolution applications. Comput Geosci 29(2):155-171

Geiermann J, Schill E (2010) 2-D Magnetotellurics at the geothermal site at Soultz-sous-Forêts: resistivity distribution to about $3000 \mathrm{~m}$ depth. CR Géosciences 342:587-599

Gehman CL, Harry DL, Sanford WE, Stednick JD, Beckman NA (2009) Estimating specific yield and storage change in an unconfined aquifer using temporal gravity surveys. Water Resour. Res., 45 supress 2009, p. 16. http://dx.doi.org/ 10.1029/2007WR006096

Genter A, Evans K, Cuenot N, Fritsch D, Sanjuan B (2010) Contribution of the exploration of deep crystalline fractured reservoir of Soultz to the knowledge of enhanced geothermal systems (EGS). CR Geosciences 342:502-516

Genter A, Cuenot N, Melchert B, Moeckes W, Ravier G, Sanjuan B, Scheiber J, Schill E, Schmittbuhl J (2013) Main achievements from the multi-well EGS Soultz project during geothermal exploitation from 2010 and 2012, extended abstract. EGC 2013, Pisa, Italy

Geuzaine C, Remacle J-F (2009) Gmsh: a three-dimensional finite element mesh generator with built-in pre- and post-processing facilities. Int J Numer Methods Eng 79(11):1309-1331

Greco F, Currenti G, D'Agostino G, Germak A, Napoli R, Pistorio A, Del Negro C (2012) Combining relative and absolute gravity measurements to enhance volcano monitoring. Bull Volcanol 74:1745-1756. doi:10.1007/s00445-012-0630-0

Hare JL, Ferguson JF, Brady JL (2008) The 4D microgravity method for waterflood surveillance: Part IV—-modeling and interpretation of early epoch 4D gravity surveys at Prudhoe Bay, Alaska. Geophysics 73:WA173-WA180. doi:10.1190/1.2991120

Hautmann S, Gottsmann J, Camacho AG, Fournier N, Sacks IS, Sparks RSJ (2010) Mass variations in response to magmatic stress changes at Soufriere Hills Volcano, Montserrat (WI): insights from 4-D gravity data. Earth Planet Sci Lett 290:83-89. doi:10.1016/j.epsl.2009.12.004

Hector B, Hinderer J, Séguis L, Boy J-P, Calvo M, Descloitres M, Rosat S, Galle S, \& Riccardi U (2014) Hydro-gravimetry in West-Africa: first results from the Djougou (Benin) superconducting gravimeter. J Geodyn. 80:34-49 http://dx.doi.org/10.1016/j.jog.2014.04.003

Hector B, Séguis L, Hinderer J, Wubda M, Descloitres M, Benarrosh N (2015) Hybrid gravimetry and water storage changes in a headwater basement catchment of Sudanian West-Africa: Water Resources Research., in revision

Heimlich C, Masson F, Gourmelen N (2013) Geodetic monitoring strategy at the geothermal sites of Soultz-sous-Forêts and Rittershoffen (Upper Rhine Graben, France). 2nd European Geothermal Workshop, Strasbourg, France

Hinderer J, Crossley D and Warburton RJ (2007) Superconducting gravimetry. in: (ed) Herring T, Schubert G. Treatise on Geophysics 3 (Geodesy), Elsevier, Amsterdam, The Netherlands. 65-122.

Hinderer $J$ et al (2012) Land water storage changes from ground and space geodesy: first results from the GHYRAF (Gravity and Hydrology in Africa) experiment. Pageoph 169(8):1391-1410. doi:10.1007/s00024-011-0417-9

Hunt T, Bowyer D (2007) Reinjection and gravity changes at Rotokawa geothermal field, New Zealand. Geothermics 36:421-435

Hunt T, Graham D (2009) Gravity changes in the Tauhara sector of the Wairakei-Tauhara geothermal field, New Zealand. Geothermics 38:108-116

Hunt T, Sugihara M, Sato T, Takemura T (2002) Measurement and use of the vertical gravity gradient in correcting repeat microgravity measurements for the effects of ground subsidence in geothermal systems. Geothermics 31:525-543

Hwang C, Wang C-G, Lee L-H (2002) Adjustment of relative gravity measurements using weighted and datum-free constraints. Comput Geosci 28:1005-1015. doi:10.1016/S0098-3004(02)00005-5

Jacob T et al (2008) Absolute gravity monitoring of water storage variation in a karst aquifer on the larzac plateau (Southern France). J Hydrology 359(12):105-117. doi:10.1016/j.jhydrol.2008.06.020

Jacob T et al (2010) Time-lapse microgravity surveys reveal water storage heterogeneity of a karst aquifer. J Geophys Res 115, B06402. doi:10.1029/2009JB006616

Jousset P, Dwipa S, Beauducel F, Duquesnoy T, Diament M (2000) Temporal gravity at Merapi during the 1993-1995 crisis: an insight into the dynamical behaviour of volcanoes. J Volcanol Geotherm Res 100:289-320. doi:10.1016/ S0377-0273(00)00141-4

La Fehr TR (1965) The estimation of the total amount of anomalous mass by Gauss's Theorem. J Geophys Res 70:1911-1919

Longuevergne L, Boy JP, Florsch N, Viville D, Ferhat G, Ulrich P, Luck B, Hinderer J (2009) Local and global hydrological contributions to gravity variations observed in Strasbourg. J Geodyn 48(3-5):189-194 
Merlet S, Bodart Q, Malossi N, Landragin A, Santos FPD, Gitlein O, Timmen L (2010) Comparison between two mobile absolute gravimeters: optical versus atomic interferometers. Metrologia 47:L9. doi:10.1088/0026-1394/47/4/L01

Naujoks M, Weise A, Kroner C, Jahr T (2008) Detection of small hydrological variations in gravity by repeated observations with relative gravimeters. J. Geodesy, 82:543-553. http://dx.doi.org/10.1007/s00190-007-0202-9.

Naujoks M, Kroner C, Weise A, Jahr T, Krause P, Eisner S (2010) Evaluating local hydrological modelling by temporal gravity observations and a gravimetric three-dimensional model. Geophys J Int 182:233-249. doi:10.1111/j.1365-246X.2010.04615.X

Newman GA, Gasperikova E, Hoversten GM, Wannamaker PE (2008) Three-dimensional magnetotelluric characterization of the Coso geothermal field. Geothermics 37(2008):369-399

Nind C, Seigel HO, Chouteau M, Giroux B (2007) Development of a borehole gravimeter for mining applications. EAGE First Break 25:71-77

Nishijima J et al (2000) Gravity monitoring of geothermal reservoirs in the Takigami Geothermal Field, Central Kyushu, Japan - gravity changes caused by production and reinjection of geothermal fluids. J Geother Res Soc Jpn 22(2000):117-130

Oka D et al (2010) Evaluation of geothermal reservoir mass change from the gravity change at the Takigam geothermal area, Ōita Prefecture, Japan. Proceedings Thirty-Seventh Workshop on Geothermal Reservoi Engineering Stanford University, Stanford, California, January 30 - February 1, 2012, SGP-TR-194

Okubo S, Satomura M, Furuya M, Sun W, Matsumoto S, Ueki S, Watanabe H (2002) Grand design for the hybrid gravity network around the Mt. Fuji volcano. In: International Symposium on Geodesy in Kanazawa Abstract., pp 39-40

Pfeffer J et al (2011) Hydrological contribution to time - variable gravity: influence of the West African Monsoon in Southwest Niger Geophys. J Int 184(2):661-672

Pohanka V (1988) Optimum expression for computation of the gravity field of a homogeneous polyhedral body. Geophys Prospect 36:733-751

Sanjuan B, Jousset P, Pajot G, Debeglia N, De Michele M, Brach M, Dupont F, Braibant G, Lasne E, Dure F (2010) Monitoring of the Bouillante geothermal exploitation (Guadeloupe, French West Indies) and the impact on its immediate environment. Proc. World Geothermal Congress 2010, Bali, Indonesia, p 9

Schultz A, Vincent P, Rose K, Hakala A, Lopano C, Schroeder K, Urquhart S, Hare J, Beard L (2012) Newberry Volcano-novel use of 4D monitoring techniques to improve reservoir longevity and productivity in Enhanced Geothermal Systems. 21st EM Induction Workshop, Darwin, Australia, Extended Abstract 4 pp

Seigel H, Nind C, Milanovic A, MacQueen J (2009) Results from the initial trials of a borehole gravity meter for mining and geotechnical applications. 11th SAGA Biennial Technical Meeting and Exhibition, Swaziland, pp 92-96

Sofyan $Y$ et al (2010) Monitoring of mass balance model during production capacity increase at Kamojang Geothermal Field, Indonesia. Proceedings 35th Workshop on Geothermal Reservoir Engineering, Stanford, pp 431-437

Sofyan Y, Kamah Y, Nishijima J, Fujimitsu Y, Ehara S, Fukuda Y, Taniguchi M (2011) Mass variation in outcome to high production activity in Kamojang geothermal field, Indonesia: a reservoir monitoring with relative and absolute gravimetry. Earth Planet Space 63(11):1157-1167

Sugihara M, Ishido T (2008) Geothermal reservoir monitoring with a combination of absolute and relative gravimetry. Geophysics 73(6):WA37-WA47

Sugihara M, Nawa K, Nishi Y, Ishido T, Soma N (2013) Continuous gravity monitoring for $\mathrm{CO}_{2}$ geo-sequestration. Energy Procedia 37:4302-4309

Takemura T et al (2000) Gravity monitoring in Yanaizu-Nishiyama geothermal field, Japan. Proceedings World Geothermal Congress 2000, Kyushu - Tohoku, Japan, pp 2937-2941

Volpi G, Manzella A, Fiordelisi A (2003) Investigation of geothermal structures by magnetotellurics (MT): an example from the Mt. Amiata area, Italy. Geothermics 32(2003):131-145

Warburton RJ, Pillai H, Reineman RC (2010) Initial results with the new GWR iGrav superconducting gravity meter. International Association of Geodesy (IAG) Symposium Proceedings, Russia, Saint Petersbourg

Wenzel HG (1996) The nanogal software: Earth tide data processing package ETERNA 3.30, Bull. Information Marées Terrestres, no 124, 9425-9439.

Wu B, Wang Z, Cheng B, Wang Q, Xu A, Lin Q (2014) The investigation of a $\mu$ Wu level cold atom gravimeter for field applications. Metrologia 51:452-458. doi:10.1088/0026-1394/51/5/452

\section{Submit your manuscript to a SpringerOpen ${ }^{\circ}$} journal and benefit from:

- Convenient online submission

- Rigorous peer review

- Immediate publication on acceptance

- Open access: articles freely available online

- High visibility within the field

- Retaining the copyright to your article

Submit your next manuscript at $>$ springeropen.com 